\title{
Study of Molecular Mechanisms Involved in the Pathogenesis of Immune-Mediated Inflammatory Diseases, using Psoriasis As a Model
}

\author{
E.S. Piruzian ${ }^{1 *}$, V.V. Sobolev1, R.M. Abdeev², A.D. Zolotarenko', A.A. Nikolaev', \\ M.K. Sarkisova', M.E. Sautin', A.A. Ishkin', An.L. Piruzyan², S.A. Ilyina², I.M. Korsunskaya², \\ O.Y. Rahimova ${ }^{3}$, S.A. Bruskin' \\ 1 Vavilov Institute of General Genetics, Russian Academy of Sciences \\ ${ }^{2}$ Center for Theoretical Problems of Physicochemical Pharmacology, Russian Academy of Sciences \\ ${ }^{3}$ Moscow Municipal Hospital № 24, Department of Health \\ *E-mail: eleopiru@vigg.ru
}

\begin{abstract}
Psoriasis was used as a model to analyze the pathogenetic pathways of immune-mediated inflammatory diseases, and the results of bioinformatic, molecular-genetic and proteomic studies are provided. Cell mechanisms, common for the pathogenesis of psoriasis, as well as Crohn's disease, are identified. New approaches for immune-mediated diseases are discussed.

Keywords: Psoriasis, immune-mediated diseases, gene expression, proteomic analysis, gene interactions, bioinformatic analysis.
\end{abstract}

\section{INTRODUCTION:}

Psoriasis (Psoriasis vulgaris, OMMIM 177900) is a chronic inflammatory, recurring, immune-mediated skin disease that involves several other organs and systems. Psoriasis is a complicated genetically based pathology, which involves several groups of genes [1].

The most common clinical manifestations of psoriasis are the appearance of dry, red patches of skin covered with silvery scales. The affected skin is characterized by an increase of the skin cell number and consequent inflammation due to the abnormal keratinocyte differentiation and infiltration of antigen-presenting cells, activation of T-helper cells, and release of proinflammatory cytokines [1,2]. The appearance of "unaffected" or "uninvolved" skin is normal. However, the gene expression profiling shows that major changes happen in both damaged and undamaged skin of a psoriatic patient, as compared with the skin of a healthy individual [3].

It is supposed that the multi-gene nature of this disease is associated with the presence of several locuses, related to the susceptibility to the disease, known as PSORS1-PSORS9 (Psoriasis Susceptibility) and located on at least 9 chromosomes. Within these chromosomal regions several genes are mapped candidates to be involved in this pathological process [4-6]. In addition, the development of psoriasis may be influenced by several other genomic locuses [7-9]. According to the data appeared in 2008, candidate genes involved in the development of psoriasis may be located on 10 different locuses (PSORS1-PSORS10) [10]. A strong genetic basis of this disease has been confirmed by family and twin studies that show a high percentage of inheritance (up to 80\%), as well as higher concordance (about $70 \%$ ) in monozygotic twins than in dizygotic twins (up to 30\%) [8]. However, just like any other multifactorial diseases, psoriasis is influenced not only by genetic factors, but also by the environment. Many environmental factors may play a role in the development of this disease in susceptible individuals: a mechanical damage skin that may lead to the Kebner's effect (development of psoriatic lesions on the site of epidermal trauma), surgical intervention, UV-radiation, high body mass index, excessive alcohol consumption and smoking, stress factors, including physiological, psycho-emotional and cold stressors[6].

It is well known that bacterial, fungal and virus infections can influence the development of psoriasis [11, 12]. Drugs, such as $\beta$-blockers [13], angiotensin-converting enzyme inhibitors [14], antimalarial drugs [15], and lithium [16] can also trigger the development of the disease. Studies show that psycho-emotional stresses can provoke psoriasis development in $23 \%$ of the patients, medication - in 16\%, physical trauma - in $43 \%$, and infections (over all) - in $14 \%$ [17]. The other $4 \%$, perhaps, include other triggering agents.

Therefore, the main reason behind the appearance of psoriasis is unknown; however, it is obvious that this disease is a result of the combined influence of several genetic and environmental factors, as well as the patient's lifestyle. Gene profiling studies show that psoriasis is an immune-mediated inflammatory disease, where epidermal cell structure disbal- 
Table 1. Patient`s information

\begin{tabular}{|c|c|c|c|c|c|c|}
\hline & Gender & Age & $\begin{array}{c}\text { Psoriasis } \\
\text { type }\end{array}$ & PASI & PsA & Inheritance \\
\hline 1 & M & 22 & P. vulgaris & 4.0 & No & Denies \\
\hline 2 & M & 36 & P. vulgaris & 7.2 & No & Father has psoriasis \\
\hline 3 & M & 23 & P. vulgaris & 1.8 & No & $\begin{array}{c}\text { Father and brother } \\
\text { have psoriasis }\end{array}$ \\
\hline 4 & M & 51 & P. vulgaris & 9.4 & No & Mother has psoriasis \\
\hline 5 & M & 38 & P. vulgaris & 2.1 & No & Denies \\
\hline 6 & M & 57 & P. vulgaris & 4.2 & No & Father has psoriasis \\
\hline 7 & M & 51 & P. vulgaris & 2.1 & No & Denies \\
\hline 8 & M & 40 & P. vulgaris & 2.8 & No & Father has psoriasis \\
\hline 9 & M & 34 & P. vulgaris & 3.2 & No & Mother has psoriasis \\
\hline 10 & M & 49 & P. vulgaris & 11.4 & No & Denies \\
\hline
\end{tabular}

ance, as well as abnormal cell growth and differentiation, is the result of molecular stress signals that initiate an improper immune response [3].

A study of the molecular mechanisms of the development of psoriasis was performed on the clinical, bioinformatical, molecular-genetic, and proteomic levels. The ethnic backgrounds of psoriasis patients were taken into consideration, and comparison with the development of other diseases (specifically Crohn's disease and atherosclerosis) was performed.

\section{MATERIALS AND METHODS}

Skin samples collection from psoriatic patients was done under local anesthetic with the use of dermatological biopsy punch $(4 \mathrm{~mm})$. Patients received no systematic PUVA/UV therapy for a month before the skin biopsy (Table 1). Biopsy samples from unaffected skin regions were taken at a distance of $3 \mathrm{~cm}$ from the damaged skin region [3, 18, 19]. The study was approved by the local ethic committee at the Genetics Institute of the Russian Academy of Sciences (RAS) and was conducted in agreement with the principles of the Declaration of Helsinki.
To grade the severity of psoriasis, a Psoriasis Area and Severity Index (PASI) were used. To calculate overall PASI, local PASI for different body parts were first obtained, using the following formula: PASI $=$ fraction $\mathrm{x}$ area $\mathrm{x}$ (redness $\mathrm{x}$ peeling $\mathrm{x}$ thickness). Over all, PASI is equal to the sum of local PASI and can differ in range from 0 to 72. Maximum PASI in this study group was 11.4; minimal, 1.8, meaning that all the patients had an acute form of the disease. The presence or absence of psoriatic arthritis accompanying psoriasis is show in column PsA (Table 1).

Collection of atherosclerosis' autopsies was done from postmortem material. To achieve that, the abdominal aorta with signs of atherosclerosis was taken and samples from the tunica intima layer of atheromatous plaques were collected. Autopsies from the healthy part of the aorta were collected in the same manner. Samples were collected from patients who were treated for different diseases (Table 2).

RNA extraction from biopsies was done by the Qiagen Kit protocol. RNA was cleaned from DNA contamination using DNAse Qiagen ${ }^{\circledast}$.

Reverse transcription was done using Promega's reverse transcriptase M-MLV protocol.

Real-time PCR was done using the fluorescent-labelled oligonucleotide probes. Reaction was done using the chemical supplies manufactured by the company Eurogene. All of the primers and probes were synthesized by the DNA-Syntez company. GAPDH was taken as a control for the target genes expression. Results analysis was done using PCR reactions with the following conditions: reaction efficiency more than $95 \%$, correlation coefficient no less then 0.99 , and slope $-3.4 \pm$ 0.2 . Method $2^{-\Delta \Delta c t}$ was used to analyze the results of polymerase chain reaction, according to [20].

To study the proteomic profiles, samples of damaged and visually undamaged skin were used. Proteins were extracted and studied using two-dimensional electrophoresis. A silver dye was used to visualize the gel lines. The images obtained were analyzed using the Melanie II program (GeneBio, Switzerland). Protein identification was done using the methods

Table 2. Pathological diagnosis of patients with atherosclerosis

\begin{tabular}{|c|c|c|l|l|}
\hline Patient & Age & Gender & Diagnosis \\
\hline 1 & 80 & F & $\begin{array}{l}\text { Encephalopathy. Brain atrophy, internal hydrocephalis. Arthrosclerosis of brain arteries. Type II Diabetes. Sclerosis, pancreatic } \\
\text { lipomatosis. }\end{array}$ \\
\hline 2 & 70 & F & $\begin{array}{l}\text { Ischemic infraction of right-frontal lobe. Arthrosclerosis of the brain vessels with stenosis up to 50\%. Type II Diabetes. } \\
\text { Hypertension. Arthrosclerosis of heart blood vessels with stenosis up to 75\%. }\end{array}$ \\
\hline 3 & 77 & M & $\begin{array}{l}\text { Infraction of the brain in the area of the middle brain artery. Type II Diabetes. Hypertension III degree. Ischemic hear disease: } \\
\text { atherosclerotic cardiosclerosis. }\end{array}$ \\
\hline 5 & 67 & F & $\begin{array}{l}\text { Chronic stomach ulcers. Chronic intestinal ulcers. Diffuse cardiosclerosis. Postmyocardial infraction cardiosclerosis. } \\
\text { Arthrosclerosis of the coronary blood vessels with stenosis of 70\%. Type II Diabetes. Arthrosclerosis of brain vessels with } \\
\text { stenosis of 30\%. }\end{array}$ \\
\hline 6 & 80 & M & $\begin{array}{l}\text { Breast cancer. Phlebothrombosis in the right crus. Pulmonary thromboembolism of lung artery. Encephalopathy. Arthrosclerosis } \\
\text { of brain vessels with stenosis of 25\%. Chronic obstructive bronchitis, diffuse pneumosclerosis, obstructive pulmonary } \\
\text { emphysema. Gastritis. }\end{array}$ \\
\hline 7 & 64 & M & $\begin{array}{l}\text { Large postmyocardial infraction cardiosclerosis. Arthrosclerosis of the coronary blood vessels with stenosis of 75\%. Secondary } \\
\text { hypertensison. Bilateral nephrosclerosis. Chronic renal insufficiency. }\end{array}$ \\
\hline 8 & 87 & M & $\begin{array}{l}\text { Chronic alcoholic intoxication. Bilateral bronchial pneumonia. Ischemic heart disease: arthrosclerosis of the coronary blood } \\
\text { vessels with stenosis of 40\%. }\end{array}$ \\
\hline $\begin{array}{l}\text { Large postmyocardial infraction cardiosclerosis. Arthrosclerosis of the coronary blood vessels with stenosis of 50\%. Hypertension } \\
\text { of the small blood-circulation circle. Arthrosclerosis of the brain vessels with stenosis of } 30-50 \% .\end{array}$
\end{tabular}


of MALDI-TOF mass-spectrometry and nano LC-MS/MS mass-spectrometry at the Proteomic center of the Institute of Biomedical Chemistry of the Russian Academy of Medical Sciences (RAMS).

The GEO DataSets (http://www.ncbi.nlm.nih.gov/geo/) database was used to for bioinformatics analysis. The GEO DataSets database contains a number of electronic tables where the gene expression microarray results are collected. The MetaCore ${ }^{\circledR}$ program produced by GeneGo Inc (USA) was used for the analysis. The MetaCore ${ }^{\circledR}$ program established that the lowest $\mathrm{p}$-value correlates to the higher possibility of gene involvement into the process. The original threshold for the $\mathrm{p}$-value was established as equal to 0.05 .

\section{RESULTS AND DISCUSSION:}

\section{THE ROLE OF ETHNIC BACKGROUND IN THE DEVELOPMENT OF PSORIASIS}

During the last several decades, extensive knowledge has been collected showing that in addition to individual differences in the metabolism of medical compounds and system reactions to those compounds, as related to their therapeutic and side effects, there are also individual differences in people's susceptibility to diseases. The investigation of the factors that influence an individual's susceptibility to a specific disease and a patient's response to treatment was started in the 1970s under the leadership of L.A. Piruzyan [21, 22]. The necessity of tracking the kinetics of metabolic changes during the process of chemical compound interaction with biological objects was stressed [23].

One's ethnic background also plays a very important role in the development of complicated diseases, such as psoriasis. On average, $2-3 \%$ of the world's population suffers from psoriasis. However, these data vary considerably depending on the country, geographic region, and ethnic background of the patient [24]. There is a huge geographic variation in the occurrence of psoriasis (Figure 1) [25]. The huge difference in the disease's incidence between Asia and Europe is proof of the significance of the ethnic component in the development of psoriasis. It is obvious that a regional-ethnic differentiation in the occurrence of psoriasis exists [7, 8, 26]. However, data on the occurrence of psoriasis collected in different populations is somewhat contradictory, which could mean that different analytical methods were used in the col-

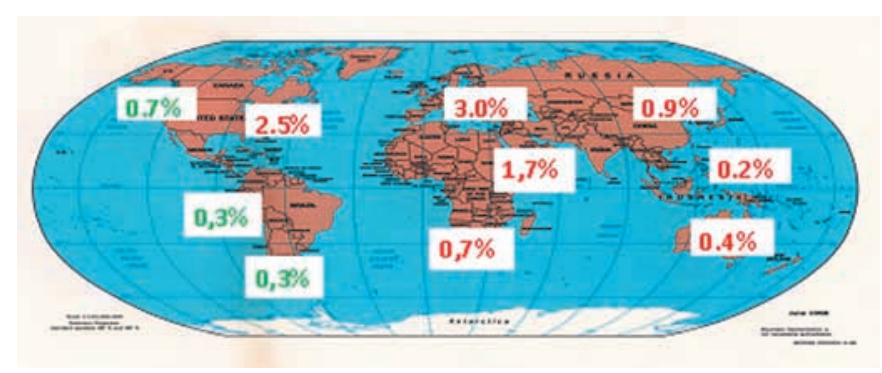

Fig. 1. Frequency distribution of psoriasis case rates in different regions of the world. The percentage of case rates in Aborigines is marked in green lection of the data. In order to make data collection easier and to standardize the analytical methods, we developed an Individual Information Card (IIC), which includes more than 50 grading profiles [27, 28]. The analysis of the genetic structures of samples from Dagestan by the IIC method, as well as family pedigrees, showed high ethnic purity, which is a result of very few marriages across ethnic groups. The consequence of this is a high level of endogamy, which leads to a rise in the degree of homozygosis in the population. Besides, the study of the genealogical trees includes a large number of families with multiple children, which provides an easier way of tracking families' structures in the space of 3-4 generations. For example, the average number of children in the families of Avarecs, Dagestanis, Lezgins, Lakcevs, Azerbaijanis, and Nogaicis is 3; the average number of children in the families of Kalmyks, Tabasarans, and Agul's is 4; but in Russian families the average number of children is only 1 . It should also be noted that in such families several generations live fairly close to each other and, therefore, are influenced by similar environmental factors.

Our study showed a significant difference in the presence of complications and duration of the disease depending on the type of illness (Type I - early, Type II - late) in the different ethnic groups of Dagestan. The data obtained in this study show the important role of the ethnic component in the inheritance of such a complicated pathology as psoriasis. The data also show that it is possible to use IIC and a model population from Dagestan to study the type of psoriasis' inheritance with reference to the ethnic component [29].

A psoriasis sensitivity gene study done on samples obtained from Russian, Tatarstan, Bashkortostan, and Hakasiyan ethnic groups in the republics of Bashkortostan and Hakasiya showed that the polymorphic gene locuses HLA-C and HCR are the basic sensitivity markers for psoriasis in the analyzed regions, regardless of the form of the disease and the ethnic group [30].

In order to study the incidence of psoriasis and for gene expression profiling, it is necessary to align all the data according to all the parameters of the study. Several differences in gene expression using Affimetrix-chips in Japanese patients with psoriasis and the results obtained with a similar method in four other study groups show variability in gene expression in individual patients based on age, gender, and environmental factors $[3,31,32,33,34]$.

\section{ANALYSIS OF BIOLOGICAL MICROARRAYS}

Today, the use of methods that allow to systematize and compress a vast pool of genetic information is widespread. This allows to explain different gene interactions. One such method is MetaCore ${ }^{\circledR}$, a program built by GeneGo Inc. (USA). As a result of gene expression microarray analysis of at least 12,000 genes using MetaCore ${ }^{\circledR}$, we concluded that 7,563 genes changed expression at least 1.5 times [35]. Figure 2 contains the list of processes changed in psoriasis-. The main processes that change under the influence of psoriasis are the immune response, cell cycle, inflammatory response, proliferation, and others. The process of disease development involves a number of immune system cells, such as T-lymphocytes (Th1, Th17), antigen-presenting cells (APC) - dendrite cells, Langerhans cells, macrophages., and natural killer (NK) cells 


\section{RESEARCH ARTICLES}

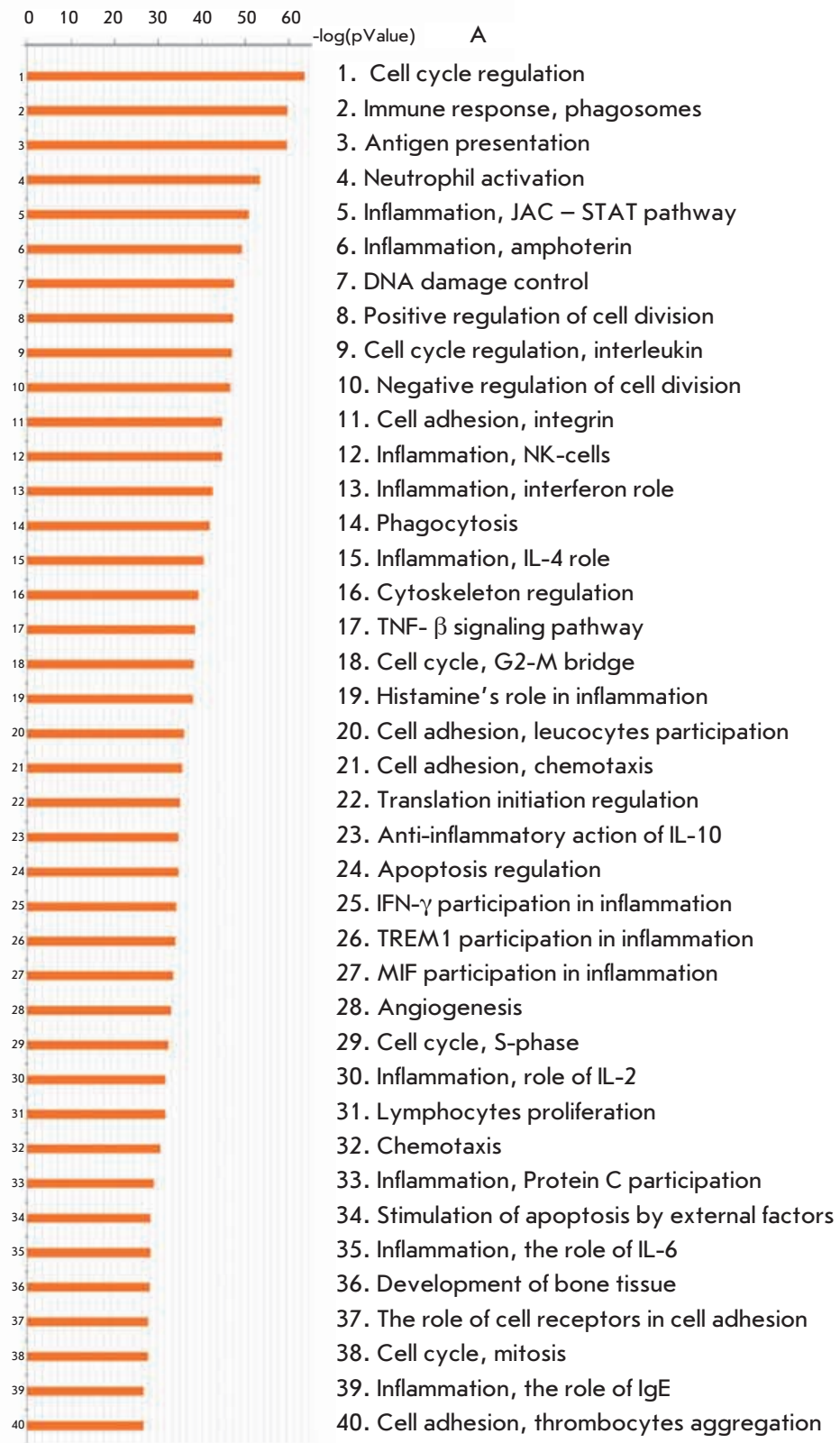

B

1. Epidermis development

2. Keratinocyte formation

3. Organization and biogenesis of cytoskeleton

4. Lipid metabolism

5. Cholesterol homeostasis

6. Filament organization

7. Keratinocyte differentiation

8. Negative cell division regulation

9. Epithelial morphogenesis

10. Regulation of muscle contractions

11. Skin development

12. Immune response

13. Muscle contractions process

14. Calcium ion homeostasis

15. Response to reactive oxygen species

16. Virus infection response

17. JAK-STA cascade

18. Glucose metabolism

19. Cell adhesion

20. Protein import into the nucleus

Fig. 2. Forty most altered processes (from the most altered to the less altered) in psoriatic skin compared to the skin of healthy volunteers (A) and twenty most altered processes (from the most altered to the less altered) in psoriatic lesions compared to the unaffected skin (B)

[36]. Cell-to-cell signaling is done with the help of signaling molecules - cytokines, as well as by the interactions of various cell receptors with their ligands. For example, receptors TLR (Toll-like receptors) belong to the family of receptors that promote an immune response when a viral or microbial presence is detected. These receptors are expressed not only on the surface of immune system cells (monocytes, macrophages, dendrite cells, and granulocytes), but also on the surface of the epithelial cells in the respiratory tract and the skin - important regions of host - pathogen interaction [37]. The TLR family includes 11 receptors, and its ligands include li- popolysaccharides, single-stranded or double-stranded RNA, lipoproteins, flagellin, and unmethylated DNA [38]. Stimulation of these receptors results in stimulation of an entire complex of signaling cascades, including NF-kappaB/Rel, IRF and MAPK - ERK, JNK, and p38. For example, MAPK induces the expression of AP-1 family transcription factors, such as Fos and Jun, and activates transcription activity in the protein complex AP-1, starting several processes leading to inflammation [39]. As a result, the expression of antiinflammatory cytokines (IL-6, IFN- $\gamma$, IL-12 and TNF- $\alpha$ ) in both induced and co-stimulating molecules, such as CD80 and 
CD86, activates the immune response [40, 41]. Considering that viruses and bacteria are the main triggers of psoriasis, these receptors play an important role in the initiation of the disease [38, 42].

In the entire family of chemokines, a high level of expression was noticed in CCR4, CCR5, CCR6, CCR10, and CXCR3. Chemokines belong to the group of anti-inflammatory cytokines and provoke an influx of Th1 cells into the inflamed regions [43]. Expression of receptors CCR4 and CCR10 usually occurs in CD4+ and CD8+ memory T-cells with CLA + phenotype (cutaneous lymphocyte antigen), which decides on the lymphocyte migration into the lymphatic nodes [44]. A ligand for the receptor CCR4 is CCL17, which is expressed on the endothelial surface of dermal blood vessels, along with ligand CCL27, and provokes the migration of leucocytes into the skin [45]. An expression level of ligand CCL27, which is a ligand for receptor CCR10, occurs in keratinocytes under the influence of anti-inflammatory cytokines IL-1 and TNF- $\alpha$. In this way, interaction of CCR10-CCL27 involves T-cells in the inflammatory process in the skin [46]. CXCL16 in atherosclerosis can be used as an example of the regulation mechanism of chemokine expression. Expression of this chemokine is induced via IL-18 through the following signaling pathway: MyD88 $\rightarrow$ IrAK1-IrAK4-TRAF6 (tumor necrosis factor receptor - associated factor 6$) \rightarrow \mathrm{c}-\mathrm{Src} \rightarrow \mathrm{PI} 3 \mathrm{~K} \rightarrow \mathrm{AKT} \rightarrow \mathrm{JNK}$ $\rightarrow$ AP-1 [47].

Data shows that the transcription factor AP-1 acts as a common link of the regulatory pathways of TLR-receptors and chemokines.

\section{ANALYSIS OF GENE-TO-GENE INTERACTIONS IN PSORIASIS}

Signal transmission from EFG (Epidermal Growth Factor) receptor inside the cell, shown in figures $3 \mathrm{a}$ and $3 \mathrm{~b}$, can be used as an example of gene-to-gene interaction in psoriasis. Both figures show that genes coding transcription factors, such as c-Fos, c-Myc, c-Jun and ELK1, are activated via signal transmission from EGFR through GRB2 and Shc to SOS, and then through the following pathway: h-Ras $\rightarrow$ c-RAF $\rightarrow$ MEK1/2 $\rightarrow$ ERK1/2 $\rightarrow$ transcription factors. Regardless of the fact that the expression levels is changed only for some genes coding corresponding mediator signals (GRB2, Shc, SOS, hRas, c-RAF, MEK1/2), like, for example c-RAF (Figure 3a), expression of transcription factor c-Fos, c-Myc, c-Jun, ELK1, and STAT3 turned out to be a lot higher in cases of damaged skin than in the undamaged skin of psoriatic patients, and higher than in the skin of healthy volunteers [35].

Figure 4 shows the degree of change in the EGF gene signaling pathway expression in the skin of psoriatic patients. We compared the threshold change (Fold Change) of gene expression in psoriasis lesions as compared to the normal skin (Figure 4a) and phenotypically healthy skin of some patients. Fold Change (FC) of expression was established as 2. Figures $4 \mathrm{a}$ and $4 \mathrm{~b}$ show some protein-to-protein interactions that are the part of signaling pathways induced by the Epidermal Growth Factor (EPF) and its ligands. Green arrows show consecutive activation of protein interaction either through bounding or phosphorylation. It is noticeable that the expression of some EGFR-ligands is higher in the psoriasis-damaged skin (HB-EGF and amphiregulin - expression increased 5.77 and 4.96 times, accordingly). Figure 4 a shows that each gene
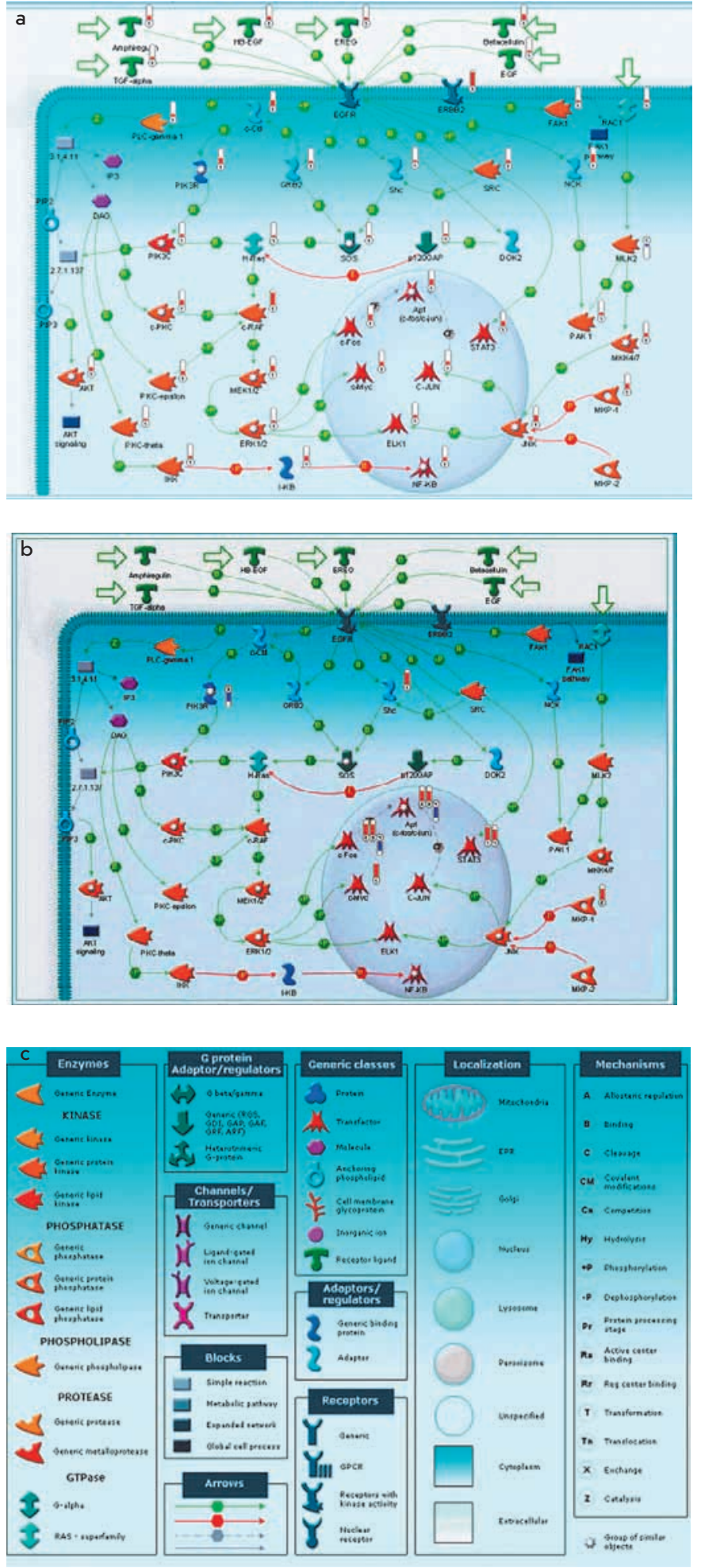

Fig. 3. Signal transduction pathway from EGF to AP-1 and alteration of expression of some genes responsible for this process during psoriasis in skin ( $A$ - skin of psoriatic patients compared to the skin of healthy volunteers, B - in affected skin compared to the unaffected skin of psoriatic patients, $\mathrm{C}$ - the notation conventions). There are also designations used on the maps that characterize the alteration of the level of expression of genes: - downregulation ; upregulation 


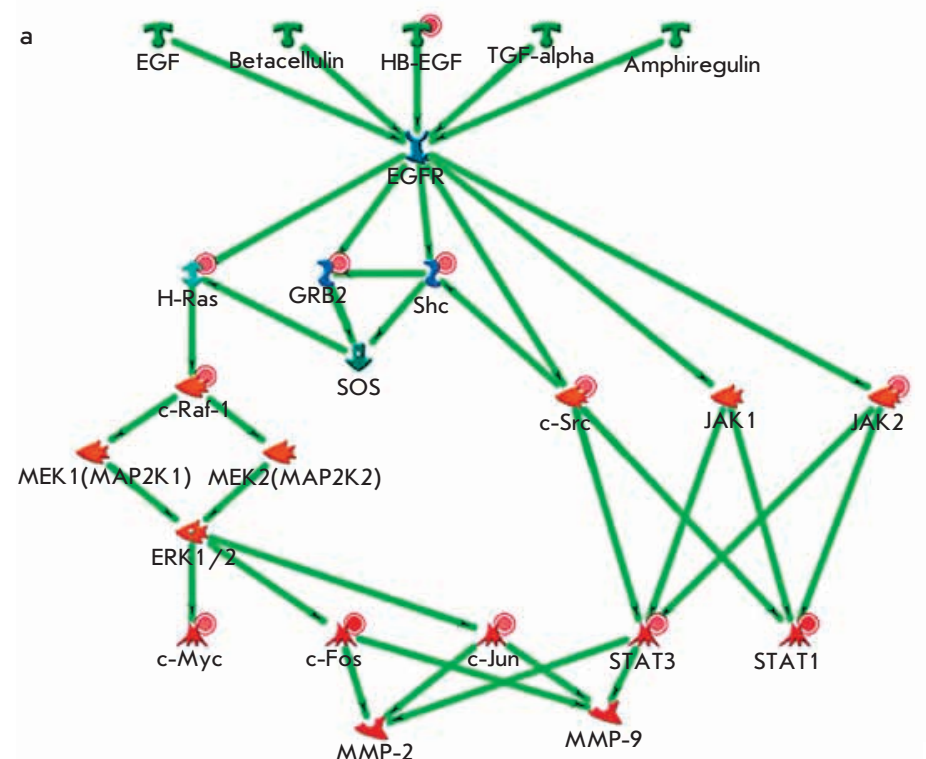

c

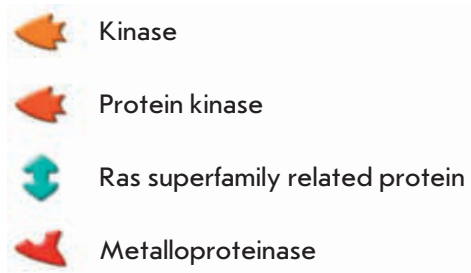

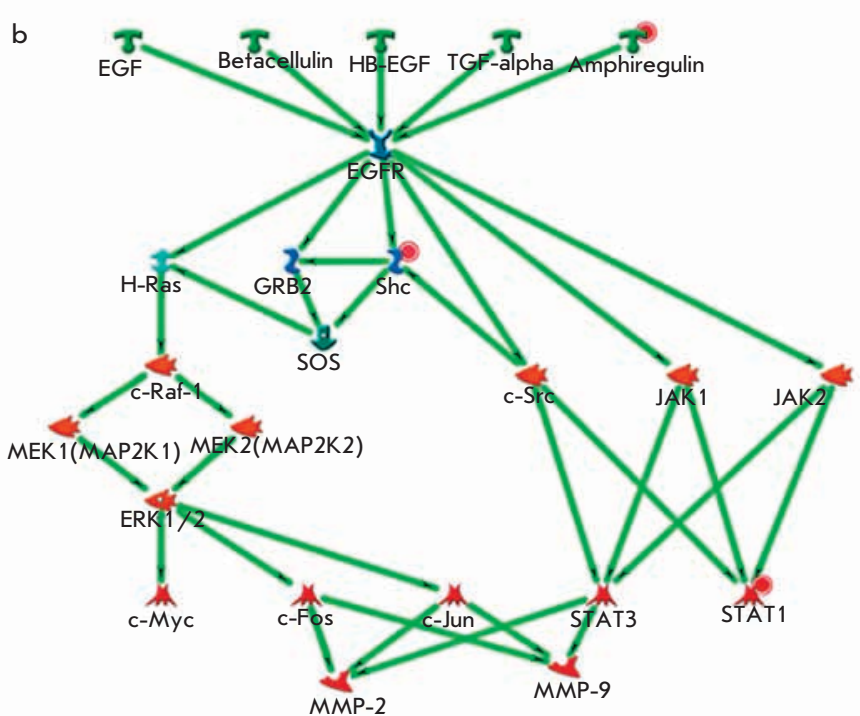

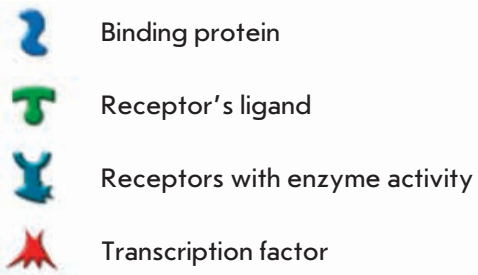

Fig. 4. Level of expression alteration of EGF signal transduction pathway genes in the skin of psoriatic patients: A- as compared to the skin of healthy individuals, B- in affected skin compared to the phenotypically normal skin of the same patients, B - the notation conventions. The hue of the color depends on the absolute value of the expression change (the bigger the change, the more saturated the color)

coding the proteins of the signaling pathway is upregulated; for example, c-Raf kinase with $\mathrm{FC}=4.46$ and c-Src with $\mathrm{FC}=$ 3.96. Moreover, transcription factors themselves are upregulated as well. Therefore, the expression of c-Myc is increased 6 and 15 times; c-Jun, 3.35 times; STAT1, 17 times; and cJun, 34 times. The general picture of gene expression changes is shown in Figure 4b. STAT3 is upregulated 8.6 times. This leads to the conclusion that the cells involved in this pathological process are characterized by a significant change in the levels of gene expression, involving a significant number of various molecular pathways and their associated transcription factors in this complicated process. A close look needs to be taken at the overexpression of those transcription factors, since under normal conditions these transcription factors do not show such sudden changes in the expression levels. The uninvolved - meaning visually healthy - skin of psoriatic patients is somewhere in between the skin of the healthy individual and the inflamed skin of the patient, since the difference between samples collected from the visually healthy skin of a psoriatic patient and damaged skin is significant, but not as significant as the difference between the damaged skin of a patient and the skin of a healthy individual.

After the analysis of gene interactions, we concluded that in all of the processes studied the main transcription factors that changed their expression in psoriasis, only components of transcription factor $\mathrm{AP}-1$ and transcription factor $\mathrm{NF}-\mathrm{kB}$ are present. Transcription factor NF-kB is activated during the immune response. In this particular study, we analyzed the role of components of transcription factor AP-1 [48].

\section{TRANSCRIPTION ANALYSIS}

Our group had a significant interest in the comparison of the level expression of genes in the damaged skin regions of psoriatic patients as compared to the expression of the same genes in the visually unaffected skin regions located no farther than $3 \mathrm{~cm}$ from the affected regions. This kind of comparison was done in several other laboratories around the world $[3,18$, 19], and it allows for maximum purity of the experiment. A threshold of change of the expression levels was established for each of the genes equal to 2. Based on a search of the literature and several databases, we established a number of genes that may be important for experimental study. These genes include genes that code transcription factor AP-1 (CJUN, JUNB, JUND, C-FOS, FOSB, FRA-1, FRA-2, and others).

Using a real-time polymerase chain reaction, we were able to analyze the levels of gene expression for 12 genes in the damaged skin and compare it with the visually unaffected 
skin of the same psoriatic patient (data not shown). Results of this experiment showed that practically all patients showed a more than doubled expression of gene FRA-1 in the damaged skin compared to the visually unaffected skin regions (Figure $5)$. All other genes differed in the direction of change of their expression.

For comparison, we were able to analyze the expression levels of gene FRA-1 in the samples obtained from the atherosclerotic patients.

Results obtained with real-time PCR showed an increase in the expression of gene FRA-1 in all patients in the atherosclerosis-affected region of the blood vessels and those suffering from skin psoriasis (Figure 6). At the same time, pathological activation of FRA-1 expression, as a component of AP-1, can lead to an increase in $I L-2$ expression and the consequential stimulation of auto-reactive cytotoxic T-lymphocytes, followed by an increase in the production of anti-inflammatory cytokines and autoantibodies, resulting in the development of a local inflammatory process, which is common in the appearance of psoriasis and atherosclerotic lesions [49, 50]. Increased expression of FRA-1 can also lead to an increase in the expression of $I L-18$, which induces transcription and expression of MMP9 (matrix metalloproteinase 9) and stimulates production of the active form MMP9. This stimulation leads to an increase in smooth muscles cell migration, which is an important part of the appearance of atherosclerotic plaques [51]. Therefore, we can conclude that it is possible that FRA1 plays a crucial role in the pathogenesis of psoriasis and atherosclerosis.

Therefore, with the help of the bioinformatic analysis, the psoriatic gene networks were examined to detect the presence of relatively closed processes, and the main genes were identified: the regulators of the transcription complex AP1. Transcription profiling of selected genes (C-JUN, JUNB, JUND, C-FOS, FRA-1 and FRA-2) based on RNA of 6 chosen genes showed a multidirectional regulation of these genes in psoriasis (data not shown). Gene FRA-1 stands out from the

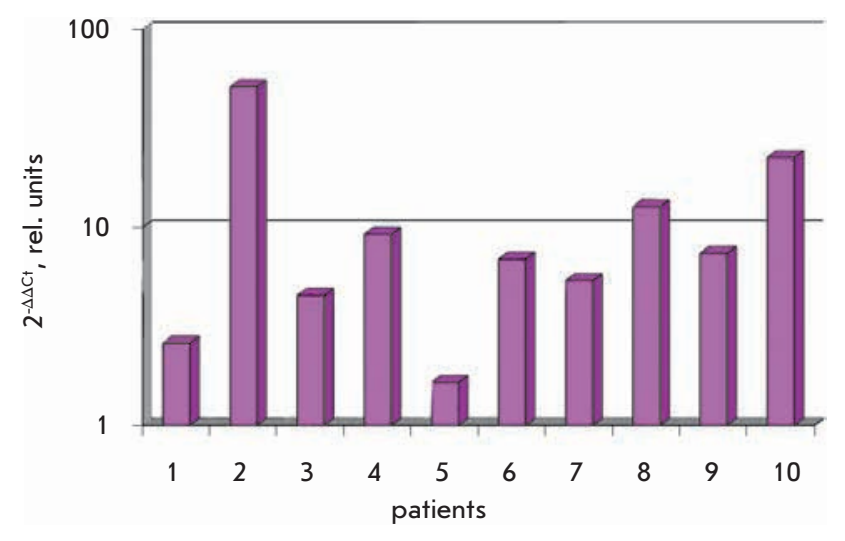

Fig.5. Level of expression alteration of FRA-1 in affected psoriatic skin relative to the visually unaffected skin of the same patients (1-absence of expression alteration; $<1$ - decrease in expression in affected sample; $>1-$ increase in expression in affected sample) other genes analyzed that code the proteins of AP-1 complex (shown on Figure 5). Moreover, change in the expression of this gene before and after treatment showed a clear tendency toward a lowering of the levels of mRNA of this gene, which correlated with the positive dynamic in the patients' illness history (data not shown). Therefore, the transcription activity of FRA-1 gene complex AP-1 may be a sort of efficiency indicator of treatment at the molecular level.

\section{PROTEOMIC STUDY}

The final goal of our study was to analyze the changes occurring in the metabolic pathways which lead to the pathogeneses, since on that level we can identify new targets for medical treatment and new approaches to pharmacological therapy can be found.

With the help of the proteomic analysis of psoriatic skin samples, we were able to establish 10 protein markers present only in the psoriasis-affected skin samples but absent in the unaffected skin samples (Table 3) [52]. A few protein families were of the biggest interest.

The S100 family includes at least 13 proteins, and the genes that code them are localized in cluster form on the $1^{\text {st }}$ chromosome (1q21), which correlates to the psoriasis susceptibility locuse PSORS4. It is known that this protein is highly expressed in the psoriasis-affected skin; however, today this gene is no longer considered a candidate for the development of psoriatic processes. At this point, the exact role of this protein remains unknown.

Proteins SCCA1 and SCCA2 belong to the family of serine proteinase inhibitors. Some studies [53] have shown that protein SCCA1 is expressed in the normal skin, while in the psoriasis affected skin its expression is twice higher.

Protein SCCA2 is not expressed in the control samples, and in the psoriasis-affected skin samples its expression levels are similar to that of SCCA1.

These proteins can be considered as potential targets for the pharmacological compounds in psoriasis treatment [54].

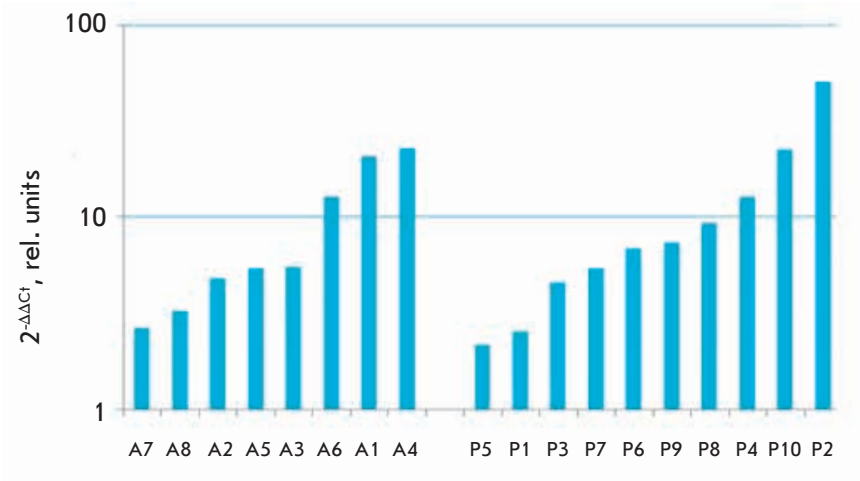

Fig. 6. Level of expression alteration of FRA-1 gene in atherosclerosis affected vassels compared to visually unaffected (A1-A8) and psoriasis affected skin compared to unaffected (P1-P10). 1- absence of expression alteration; $<1$ - decrease of expression in affected sample; $>1$ increase of expression in affected sample) 


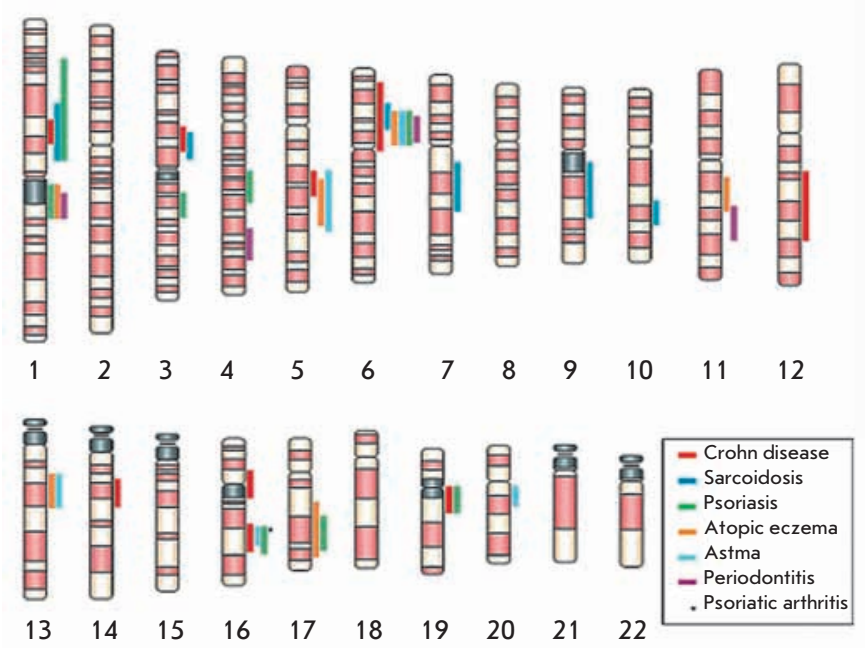

Fig.7. Clustering of linkage regions and disease genes in human inflammatory barrier disease [55]

\section{COMPARATIVE ANALYSIS OF PSORIASIS AND CROHN'S DISEASE PATHOGENESIS}

A multidimensional study of the molecular mechanisms of psoriatic pathogenesis can be considered as a model for the study of the pathogenesis of other immune-mediated inflammatory diseases (IMID - Immune-mediated inflammatory disorders), which are characterized by acute and chronic inflammatory conditions. The most common IMIDphenotypes are Crohn's disease, ankylosing spondylitis, rheumatoid arthritis, psoriasis, uveitis, and psoriatic arthritis. The central role in all of these diseases is played by the cytotoxin TNF- $\alpha$ (tumor necrosis factor - alpha). Figure 7 shows the localization of gene groups responsible for the development of these diseases [55]. Crohn's disease and ulcerative colitis are chronic inflammatory diseases that are generally called IBD (inflammatory bowel disease). Both twin

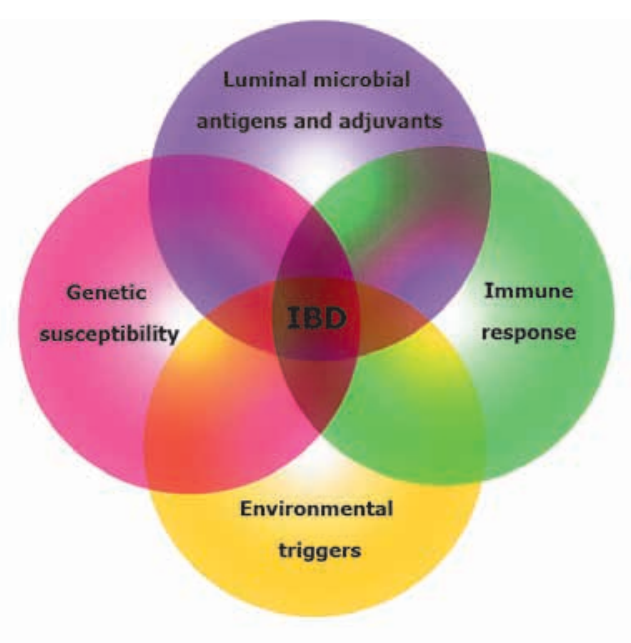

Fig. 8. The interaction of different factors (genetic susceptibility, environmental triggers, luminal microbial antigens and adjuvants, immune response) that cause chronic-inflammation intestine process[56]

studies and the generally higher incidence of these diseases in close relatives point to a genetic basis for these diseases. The increase in the number of cases in Europe and North America since the second half of the $20^{\text {th }}$ century is an indication of the strong influence of environmental factors, with relatively low levels of concordance in the monozygotic twins ( $50 \%$ for the Crohn's disease and $10 \%$ for the ulcerative colitis). Even though animal studies do provide clues about the etiology of Crohn's disease, its nature remains a mystery [55, 56].

The most whidespread hypothesis about IBD pathogenesis is the presence of a heavy $\mathrm{T}$-cell immune response to certain environmental factors and some pathogenic enterobacteria in the genetically susceptible individuals, which increases the beginning or reactivation of the disease. Figure 8 shows the activation of four independent components, the interaction of which at different points of the disease's

Table 3. Proteins identified as different at involved and uninvolved psoriatic skin [52]

\begin{tabular}{|c|c|c|c|}
\hline \multirow{2}{*}{ Blot, number } & \multirow{2}{*}{ Protein name } & \multicolumn{2}{|c|}{$\% \mathrm{Vol}$} \\
\hline & & Affected skin & Unaffected skin \\
\hline \multirow{3}{*}{1} & Keratin 17 & \multirow{3}{*}{$1.97 \pm 0.92$} & \multirow{3}{*}{$0.18 \pm 0.06$} \\
\hline & Keratin 14 & & \\
\hline & Keratin 16 & & \\
\hline 2 & SCCA2/SCCA1 & $0.28 \pm 0.09$ & $0.066 \pm 0.02$ \\
\hline 3 & Squamous cell carcinoma antigen; SCC antigen & $0.35 \pm 0.18$ & $0.03 \pm 0.01$ \\
\hline 4 & Enolase 1 & $0.87 \pm 0.22$ & $0.40 \pm 0.14$ \\
\hline 5 & Superoxide dismutase [Mn] & $0.22 \pm 0.03$ & $0.11 \pm 0.02$ \\
\hline 6 & Galectin $7 ; \mathrm{Gal}-7$ & $1.14 \pm 0.41$ & $0.19 \pm 0.01$ \\
\hline 7 & Protein S100 - A9 & $0.54 \pm 0.03$ & 0 \\
\hline 8 & Protein S 100 - A9 & $0.15 \pm 0.07$ & 0 \\
\hline 9 & Protein S100-A7 (Psoriasin) & $0.51 \pm 0.16$ & 0 \\
\hline 10 & Protein S100-A7 (Psoriasin) & $1.36 \pm 0.37$ & $0.02 \pm 0.03$ \\
\hline
\end{tabular}


Table 4. The list of genes common for pathogenesis of psoriasis and Crohn's disease.

\begin{tabular}{|c|c|c|c|c|c|}
\hline Gene & Identification Number & Location & Gene & Identification Number & Location \\
\hline GNA15 & 2769 & $19 \mathrm{p} 13.3$ & CBX3 & 11335 & $7 \mathrm{p} 15.2$ \\
\hline GPM6B & 2824 & $\mathrm{Xp} 22.2$ & UGT1A6 & 54578 & $2 q 37$ \\
\hline OAS2 & 4939 & $12 q 24.2$ & PSME2 & 5721 & $14 q 11.2$ \\
\hline FOXC1 & 2296 & $6 \mathrm{p} 25$ & TRAK2 & 66008 & $2 q 33$ \\
\hline ZNF207 & 7756 & $17 q 11.2$ & DNAJC7 & 7266 & $17 q 11.2$ \\
\hline STAT3 & 6774 & $17 q 21.31$ & TRIM22 & 10346 & $11 \mathrm{p} 15$ \\
\hline TXNDC1 & 81542 & $14 q 22.1$ & IRF9 & 10379 & $14 q 11.2$ \\
\hline MRPL9 & 65005 & $1 q 21$ & UBE2L6 & 9246 & $11 \mathrm{q} 12$ \\
\hline CASP4 & 837 & $11 \mathrm{q} 22.2-\mathrm{q} 22.3$ & ETS2 & 2114 & $21 \mathrm{q} 22.2$ \\
\hline MECP2 & 4204 & $\mathrm{Xq} 28$ & QPCT & 25797 & $2 \mathrm{p} 22.2$ \\
\hline LONRF1 & 91694 & $8 \mathrm{p} 23.1$ & SFPQ & 6421 & $1 \mathrm{p} 34.3$ \\
\hline VKORC1 & 79001 & $16 \mathrm{p} 11.2$ & H2AFY & 9555 & $5 q 31.3-q 32$ \\
\hline MIB1 & 57534 & $18 q 11.2$ & HMGN1 & 3150 & $21 \mathrm{q} 22.2$ \\
\hline RFK & 55312 & $9 q 21.13$ & CTSC & 1075 & 11q14.1-q14.3 \\
\hline SOSTDC1 & 25928 & $7 \mathrm{p} 21.1$ & SERPINB5 & 5268 & $18 q 21.3$ \\
\hline KIAA1033 & 23325 & $12 \mathrm{q} 24.11$ & IER2 & 9592 & $19 \mathrm{p} 13.13$ \\
\hline SYNCRIP & 10492 & $6 q 14-q 15$ & S100A8 & 6279 & $1 q 21$ \\
\hline RARG & 5916 & $12 q 13$ & ARMET & 7873 & $3 \mathrm{p} 21.1$ \\
\hline DDOST & 1650 & $1 \mathrm{p} 36.1$ & FGFR2 & 2263 & $10 \mathrm{q} 26$ \\
\hline CDC42EP1 & 11135 & $22 q 13.1$ & RBPMS & 11030 & $8 \mathrm{p} 12-\mathrm{p} 11$ \\
\hline S100A9 & 6280 & $1 q 21$ & JUNB & 3726 & 19 p13.2 \\
\hline PHGDH & 26227 & $1 \mathrm{p} 12$ & & & \\
\hline
\end{tabular}

development is necessary for its clinical implications. From our point of view, comparable studies of the genetic factors involved in the pathogenic pathways of psoriasis and Crohn's disease can play a significant role in the deciphering of the molecular mechanisms of the pathogenesis of these diseases. A comparative bioinformatics analysis of microarray database GEO Data Sets allowed to prepare a general list of the genes that undergo changes in the cell processes of both diseases.

IDENTIFICATION OF GENES THAT CHANGE THEIR EXPRESSION IN BOTH PATHOLOGIES - PSORIASIS AND CROHN'S DISEASE

Our research was focused on the identification of differentially expressed genes in each data set and comparison of these lists of genes at the systemic level. The approach we took in working on this problem was dictated by the character of the expression data (high noise level, large amount of data to be analyzed) and the attributes of each individual data set taken for the analysis (they were done on different types of microarrays that have different numbers of probes and, therefore, cannot be compared directly) [57].

Originally, psoriasis data sets contained information on the expression of 12,626 probes for 8 experiments ( 4 samples of damaged skin and 4 samples of healthy skin). When probes with badly detectable expression were thrown out, the number of probes was reduced to 5,076 . The list of probes with statistically significant differences in expression be- tween the affected and unaffected skin samples contained 410 probes with a significance level of 0.1 .

The data sets for Crohn's disease contained information on expression levels for 24,016 probes in 21 experiments ( 10 intestinal epithelial samples of healthy individuals and 11 epithelial samples of damaged epethilia). The list of probes with statistically significant differences in expression between the damaged and undamaged tissues was 3,850 probes, with a significance level of 0.1 . Such a huge difference in the probe lists' sizes was due to the fact that the algorithm to control Type I errors (FDR) depends on the size of the input set: the larger the number of genes in the input set, the larger the number of genes taken with the same p-value distribution that will go through FDR control. In our study, the number of analyzed probes in the Crohn's disease data set is five times that of the psoriasis data.

The resulting data sets of differentially expressed genes were introduced into the MetaCore ${ }^{\circledR}$. Since microarrays contain not only probes for the genes studied, but also for a large number of EST with unclear roles, in this step the size of the genes lists changed because not all of the probes have a correlating gene in the MetaCore ${ }^{\circledR}$ database, and because some probes correlate to more than one gene. The size of the genes lists changed to 425 genes for psoriasis and 2,033 for Crohn's disease.

These genes lists had 49 common genes, and the level of similarity is rather significant $(\mathrm{p}$-value $=4.94 \times 10-2)$. Fisher's 
test was used to grade this significance; 9,017 genes present in the two study data sets were taken. Identification of these genes was done by comparing the genes lists for both gene microarray sets in MetaCore ${ }^{\circledR}$.

Forty-nine genes were selected for the further analysis and are shown in table 4 . The cell molecular-genetic processes associated with the genes common to psoriasis and Crohn's disease were of a particular interest. Program methods in MetaCore ${ }^{\circledR}$ were used to create Table 5 , where the most possible cell processes involving genes from Table 4 are shown. The processes shown in Table 5 can be divided into two categories: those participating in inflammation processes and those participating in the regulation of the cell cycle. In both psoriasis and Crohn's disease, the main pathological focus lies in the focus of inflammation. Cell cycle and apoptosis are disturbed in psoriasis. Keratinocytes in the focus of the inflammation have no time to apoptose due to extra proliferation; thus, they form the skin patches we observe in psoriasis. Similar processes take place in the intestine of Crohn's disease's patients.

\section{REASONABLE APPROACHES TO THE PHARMACOLOGICAL TREATMENT OF PSORIASIS AND POSSIBLE NEW APPROACHES TO THE TREATMENT OF IMMUNE- MEDIATED INFLAMMATORY ILLNESSES}

Psoriasis is considered a recurrent incurable illness; its treatment focuses on lengthening the remission periods and reducing the severity of the disease. The drugs used (cyclosporine, system retinoids and fumarates) lead only to a temporary improvement of the patient's condition. Nonetheless, some new approaches are being explored. New therapeutic methods are characterized by a more specific influence on the specific molecular targets that play a key role in the formation of the pathological processes in psoriasis. They include modificators of the biological response, such as alefacept, efalizumab, etarnecept, infliksimab, and adalimumab, which specifically target the molecular mediators involved in the immune-pathogenesis of psoriasis (receptors and ligands). For example, the suppression of $\mathrm{TNF} \alpha$ activity, a key cytokine in the innate immune response, is achieved through three inhibitors of $\mathrm{TNF} \alpha$ (alefacept, etarnecept, and infliksimab). Etarnecept is a two-component protein produced from the ligand-binding fragment receptor $\mathrm{TNF}$ attached to the $\mathrm{Fc}$-fragment IgG1. It binds TNF and blocks its interaction with cell-surface receptors, reducing the inflammation process. Infliksimab - TNF $\alpha$ human monoclonal antibodies lower the activity of $\mathrm{TNF} \alpha$, which lowers the production of $I L-1$ and $I L-6$ [58]. Therefore, the new generation of biological approaches to the treatment of psoriasis focus on the specific destruction of targets for the T-cell mediated pathogenic processes.

A number of successful attempts at psoriatic arthritis treatment with bio-modificators have been documented since 2001 [58, Abstract book of Third EAD International Spring Symposium, Sofia, 2005]. TNF $\alpha$ levels are increased in the intestinal mucosa during Crohn's disease; therefore, TNF $\alpha$ inhibitors are used to treat this disease. This kind of monotherapy by means of bio-modificators is used for the treatment of psoriatic arthritis and rheumatoid arthritis [59, 60].
Table 5. The common cell processes typical for psoriasis and Crohn's disease

\begin{tabular}{|c|c|}
\hline Processes & P-value \\
\hline Inflammation: interferon signaling pathway & $2.19 \mathrm{E}-03$ \\
\hline Signal transmission: WNT signaling pathway & $1.20 \mathrm{E}-02$ \\
\hline Regulation of translation initiation & $5.66 \mathrm{E}-02$ \\
\hline Morphogenesis of blood vessels & $9.76 \mathrm{E}-02$ \\
\hline DNA repair & $1.17 \mathrm{E}-01$ \\
\hline Inflammation: amphoterine signaling pathway & $1.19 \mathrm{E}-01$ \\
\hline Cell cycle and apoptosis driven proteolysis & $1.29 \mathrm{E}-01$ \\
\hline Interleukin regulation of cell cycle in G1-S phase & $1.29 \mathrm{E}-01$ \\
\hline Signal transmission: androgen receptor signaling pathways & $1.34 \mathrm{E}-01$ \\
\hline
\end{tabular}

However, a number of unusual side effects associated with this treatment have been reported. For example, some reseachers have indicated the development of psoriatic lesions on the skin of some Crohn's disease patients [60, 61, 62]. The mechanisms leading to such serious side effects are unclear; therefore, continued research in this area on the moleculargenetic level is necessary.

In conclusion, the main goal of investigations of the pathways leading to the pathogenesis of immune-mediated diseases on the molecular level is to find new pharmacological treatment options. The proteomic studies of skin samples affected by psoriasis and intestinal fragments affected by Crohn's disease performed by our research group are geared toward finding new targets for pharmacological treatment options. It is also necessary to compare the obtained data with the results of the meta-analysis of development pathways for these two immune-mediated inflammatory diseases done by us.

We used psoriasis as an example to show the necessity of an integrated approach to the deciphering of the disease's pathogenesis stages, including clinical and bioinformatical analysis, as well as analysis of metabolic and genetic data, which will assist in the development of simple methods of individual characterization of pathogenesis and finding more effective methods for the treatment of each individual. In this manner, psoriasis is taken as a typical complicated disorder and is considered an adequate model for the study of the pathogenicity mechanisms for other disorders similar to psoriasis in their influence on human life.

The work was supported by the Russian Federal Agency for Science and Innovation (federal contract 02.512.11.2231) and the Presidium of Russian Academy of Sciences, as a part of the program "Fundamental Medical Science." 
REFERENCES

1. Lowes M.A., Bowcock A.M., Krueger J.G. Pathogenesis and therapy of psoriasis. // Nature. 2007. V. 445 P. 866-873

2. Bowcock A. M. and Krueger J. G. Getting under the skin: the immunogenetics of psoriasis. // Nat. Rev. Immunol. 2005. V. 5. P. 699-711.

3. Kulsky J.K., Kenworthy W., Bellgard M. et al. Gene expression profiling of Japanese psoriatic skin reveals an increased activity in molecular stress and immune response signals // J. Mol. Med. 2005. V. 85. P. 964-975.

4. Barker J. N. Genetic aspects of psoriasis. // Clin. Exp. Dermatol. 2001. V. 26. № 4. P. $321-5$.

5. Prinz J. C. Psoriasis vulgaris-a sterile antibacterial skin reaction mediated by crossreactive T cells? An immunological view of the pathophysiology of psoriasis. // Clin. Exp. Dermatol. 2001. V. 26. № 4. P. 326-32.

6. Bowcock A. M. and Cookson W. O. The genetics of psoriasis, psoriatic arthritis and atopic dermatitis. // Hum. Mol. Genet. 2004. V. 13. № 1. P. R43-55.

7. Asumalahti K., Veal C., Laitinen T. et al. Psoriasis Consortium. Coding haplotype analysis supports HCR as the putative susceptibility gene for psoriasis at the MHC PSORS1 locus. // Hum. Mol. Genet. 2002. V. 11. P. 589-597.

8. Sagoo G.S., Cork M.J., Patel R. et al. Genome - wide studies of psoriasis susceptibility loci: a review. // Joural of Dermatological Science. 2004. V. 35. P. 171-179.

9. Fun X., Yang S., Huang W. et al. Fine mapping of the psoriasis susceptibility locus PSORS1 support HLA-C as the susceptibility gene in the Han Chinese population. // PLoS Genet. 2008. V. 4. P. 1-10

10. Duffin K.C., Chandran V., Krueger G.G. et al. Genetics of Psoriasis and Psoriatic Arthritis: update and future direction (GRAPPA 2007) // J. Rheumatology. 2008. V. 35. № 7. P. $1449-1453$.

11. Duvic M., Johnson T.M., Rapini R.P. et al. Acquired immunodeficiency syndrome-associated psoriasis and Reiter's syndrome. // Arch. Dermatol. 1987. V. 123. P. 1622-1632

12. Swerlick R.A., Cunningham M.W., Hall N.K. Monoclonal antibodies cross-reactive with group A streptococci and normal and psoriatic human skin. // J. Invest. Dermatol. 1986. V 87. P. $367-371$

13. Gold M.H., Holy A. K., Roenigk H. H. Jr. Beta-blocking drugs and psoriasis. A review of cutaneous side effects and retrospective analysis of their effects on psoriasis. // J. Am. Acad. Dermatol. 1988. V. 19. P. 837-841.

14. Wolf R., Tamir A., Brenner S. Psoriasis related to angiotensin-converting enzyme inhibitors. // Dermatologica. 1990. V.181. P. 51-53.

15. Baker H. Psoriasis - clinical features. // Br. Med. 1971. V. 3. P. 231-233.

16. Lazarus G.S., Gilgor R.S. Psoriasis, polymorphonuclear leukocytes, and lithium carbonate. An important clue. // Arch. Dermatol. 1979. V. 115. P. 1183-1184.

17. Asumalahti K. Molecular genetics of psoriasis. // Helsinki university biomedical disseration. № 27. 2003.

18. Sonkoly E., Wei T., Janson P.C., Saaf A. et al. MicroRNAs: novel regulators involved in the pathogenesis of Psoriasis? // PLoS ONE. 2007. V. 2. № 7. P. 1-8.

19. Yao Y., Richman L., Morehouse C. et al. Type I Interferon: Potential Therapeutic Target for Psoriasis? // PLoS One. 2008. V. 3. № 7. e2737. P. 1-14

20. Livak K.J., Schmittgen T. D. Analysis of relative gene expression data using real-time quantitative PCR and the 2(-Delta Delta C(T)) Method. // Methods. 2001. V. 25. № 4. P. $402-408$

21. Podimov V.K., Gladkich S.P., Mishkin V.S., Piruzyan L.A., N-acetyltransferase polymorphism of patients with lupus erythematosus // "The problems of investigation, study and production of new drugs", Shwiesa, Kaunas - 1979, P. 52-53.

22. Piruzyan L.A. Metabolic human passport - the basis of new strategy in pharmacology // Vestnik of RAS. 2004. V.74. P. 610-618.

23. Piruzyan L.A. On pharmacological metrology // Bull. USSR Academy of Sci., Biol.. 1990. №2. P. 302-303.

24. Gudjonsson J.E, Elder J.T. Psoriasis: epidemiology. // Clinics in Dermatology. 2007. V. 25. P. 535-546.

25. Piruzyan An.L., Abdeev R.M., Sarkhisova M.K. The role of pharmacogenetics and pharmacogenomics in dermatology // Clinical dermatology and venerology. 2005. №3. P. $8-13$

26. Bowcock A.M. The genetics of psoriasis and autoimmunity. // Annu. Rev. Genomics Hum. Genet. 2005. V. 6. P. $93-122$

27. Piruzyan An.L. Doctoral diss. 2005. №3. P.352

28. Piruzyan L.A., Goldenkova I.V., Korsunskaya I.M. et al. Scientific approach to standardization of psoriatic patient's care (scientific review) // The problems of standardization in health care. 2006. №6. P. 7-13.

29. Goldenkova-Pavlova I.V., Piruzyan A.L., Abdeev R.M. et. al. Population analysis and determination of the ethnic background are necessary in the study of multifactorial diseases( a study using the Dagestan population as a model) // Genetika. 2006 V.42, №8 P.1137-42.

30. Akhmetova V.L., Galimova E.S., Yusunbaev B.B., Khusnutdinova E.K. The analysis of the genes responsible for susceptibility to psoriasis in Bashkortostan and Khakasia republics // Medical genetics. 2009. №8. P. 29-35.

31. Bowcock A.M., Shanon W., Du F. et al. Insight into psoriasis and other inflammatory diseases from large scale gene expression studies. // Hum. Mol. Genet. 2001. V. 10. P. $1793-1805$

32. Oestreicher J.L., Walters I.B., Kikichi T. et al. Molecular classification of psoriasis disease-associated genes through pharmacogenomic expression profiling. // Pharmacogenomics J. 2001. V. 1. P. 272-287.
33. Nomura I., Gao B., Boguniewicz et al. Distinct pattern of gene expression in the skin lesions of atopic dermatitis and psoriasis: a gene microarray analisys. // J. Allegry Clin. Immunol. 2003. V. 112. P. 1195-1202.

34. Zhou X., Krueger J.G., Kao M-C.J. et al. Novel mechanism of T-cell and dendritic cell activation revealed by profiling of psoriasis on the 63,100 -element oligonucleotide array. // Physiol. Genomics. 2003. V. 13. P. 69-78.

35. E.S. Piruzian, T.A. Nikolskaya, R.M. Abdeev, S.A. Brouskin, Transcription Factor AP-1 Components As Psoriasis Candidate Genes // Molecular Biology. 2007, Vol. 41, No 6, pp. $1069-1080$.

36. Sabat R., Philipp S., Höflich C., et al. Immunopathogenesis of psoriasis. // Exp Dermatol. 2007. V. 16. № 10. P. 779-98.

37. Medzhitov R., Preston-Hurlburt P., Janeway C.A. A human homologue of the Drosophila Toll protein signals activation of adaptive immunity. // Nature. 1997. V. 388. P. 394-397.

38. McInturff J.E., Modlin R.L., Kim J. The role of toll-like receptors in the pathogenesis and treatment of dermatological disease. // J. Invest Dermatol. 2005. V. 125. № 1. P. 1-8.

39. Hu X., Chen J., Wang Lu et al. Crosstalk among Jak-STAT, Toll-like receptor, and ITAM dependent pathways in macrophage activation. // Journal of Leukocyte Biology. 2007. V. 82. P. 237-243

40. Schnare M., Barton G. M., Holt A. C. et al. // Nat Immunol. 2001. V.2. № 10. P. 947-950. 41. Schjetne K.W., Thompson K.M., Nilsen N. et al. Cutting edge: link between innate and adaptive immunity: Toll-like receptor 2 internalizes antigen for presentation to CD4+T cells and could be an efficient vaccine target. // J. Immunol. 2003. V. 171. № 1. P. 32-36.

42. Perez-Lorenzo R., Zambrano-Zaragoza J. F., Moo-Castillo K. et al. IgG class antibodies to heat shockinduced streptococcal antigens in psoriatic patients. // Int J. Dermatol. 2003. V. 42. P. $110-115$

43. Krueger J.G. The immunologic basis for the treatment of psoriasis with new biologic agents. // J. Am. Acad. Dermatol. 2002. V. 46. № 1. P. 1-23.

44. Reiss Y., Proudfoot A.E., Power C.A. et al. CC Chemokine Receptor (CCR)4 and the CCR10 Ligand Cutaneous T Cell-attracting Chemokine (CTACK) in Lymphocyte Trafficking to Inflamed Skin. // J. Exp. Med. V. 194. № 10. 2001.

45. Lonsdorf A.S., Hwang S.T., Enk A.H.et al. Chemokine Receptors in T-Cell-Mediated Diseases of the Skin // J. Invest. Dermatol. 2009

46. Honey B., Alenius H., Muller A. et al. CCL27-CCR10 interactions regulate T cellmediated skin inflammation. // Nat. Med. 2002. V. 8. P. 157-65.

47. Chandrasekar B., Mummid S., Valente A. et al. The Pro-atherogenic Cytokine Interleukin-18 Induces CXCL16 Expression in Rat Aortic Smooth Muscle Cells via MyD88, Interleukin-1 Receptor-associated Kinase, Tumor Necrosis Factor Receptor-associated Factor 6, c-Src, Phosphatidylinositol 3-Kinase, Akt, c-Jun N-terminal Kinase, and Activator Protein-1 Signaling. // The Journal of biological chemistry. 2005. V. 280. № 28. P. $26263-26277$.

48. Turpaev K.T. 2006. Role of transcription factor AP-1 in integration of intracellular signal pathways. // Mol. Biol. 40, 945-961.

49. Gonsky R., Deem R.L., Hughes C.C. et al. Activation of the CD2 pathway in lamina propria $\mathrm{T}$ cells up-regulates functionally active AP-1 binding to the IL-2 promoter, resulting in messenger RNA transcription and IL-2 secretion. // J. Immunol. 1998. V. 160. № 10. P. 4914-22

50. Bantel H., Schmitz M.L., Raible A. et al. Critical role of NF-kappaB and stress-activated protein kinases in steroid unresponsiveness. // FASEB J. 2002. V. 16. № 13. P. 1832-4

51. Chandrasekar B., Mummidi S., Mahimainathan L. et al. Interleukin-18-induced human coronary artery smooth muscle cell migration is dependent on NF-kappaB- and AP-1-mediated matrix metalloproteinase- 9 expression and is inhibited by atorvastatin // J. Biol. Chem. 2006. V. 281. № 22. P. 15099-109.

52. Bruskin S. A. PhD Thesis, 2008. P. 120

53. Takeda A., Higuchi D., Takahashi T. et al. Overexpression of serpin squamous cell carcinoma antigens in psoriatic skin. // J. Invest. Dermatol. 2002 V. 118, № 1. P. 147-1454.

54. Bruskin S.A., Abdeev R.M., Moshkovskii S.A. et. al. Psoriasis proteomic research as an approach for identification of potential targets for pharmacotherapy // Clinical dermatology and venerology. 2009. №1. P.28-31.

55. Schreiber S., Rosenstiel P., Albrecht M. et al. Genetics of Chron disease, an archetypa inflammatory barrier disease. // Nature. 2005. V. 6. P. 376-388.

56. Sartor B.R. Mechanisms of Disease: pathogenesis of Crohn's disease and ulcerative colitis. // Nature Clinical Practice Gastroenterology \& Hepatology. 2006. V. 3. P. 390-407. 57. Piruzian E.S., Ishkin A.A., Nikol'Skaya T.A., Abdeev R.M., Bruskin S.A. A comparative analysis of the molecular genetic processes in the pathogenesis and Crohn's disease, 2009, V.46, №1, P. 175-179

58. Chaudhari U., Romano P., Mulcahy L.D. et al. Efficacy safety of infliximab monotherapy for plaque-type psoriasis: a randomized trial. // Lancet. 2001. V. 357. P. 1842-1847. 59. Baeten D., Kruithof E., Van den Bosch et al. Sisitematic safety follow up in a cohort of 107 patients with spondyloarthropathy treated with infliximab: a new perspective on the role of host defence in the pathogenesis of the disease? // Ann. Rheum. Dis. 2003. V. 62. P. 829-834.

60. Sfikakis P.P., Iliopopulus A., Elezoglou A. et al. Psoriasis induced by anti-tumor necrosis factor therapy: a paradoxical adverse reaction. // Arthritis Rheum. 2005. V. 52 P. $2513-2518$

61. Peramiquel L., Puig L., Dalmau J. et al. Onset of flexural psoriasis during infliximab treatment for Crohn's disease. // Clin. Exp. Dermatol. 2005. V. 30. № 6. P. 713-714. 62. Umeno J., Matsumoto T., Jo Y. et al. Psoriasis during anti-tumor necrosis factor - alpha therapy for Crohn's desease. // Inflamm. Bowel Dis. 2007. V. 13. P. 18188-1189. 